\title{
Financing diamond projects
}

\author{
by J.A.H. Campbell*
}

\section{Synopsis}

Investment in diamond exploration has been declining over the past decade, in spite of positive long-term industry fundamentals and a growing interest in diamonds as an investment category. The lack of new significant discoveries in recent years has eroded investor confidence, yet no new discoveries are possible without investment in exploration. Junior 'mine finders' have been the hardest hit. Their agility, tenacity, and appetite for risk are not sufficient to attract the funding required, even at the greenfield stage. Developing new discoveries into mineral resources can be crippling without solid financial support. Junior incubators could play a crucial role, especially at the project evaluation stage - but where are they? Alternatives to traditional funding mechanisms have become available, many still untested in the junior diamond exploration space. Valuable lessons can be drawn from the past and used to inform emerging new strategies.

\section{Keywords}

diamond exploration, project development, financing, revenue streaming, crowdfunding, incubators.

\section{Introduction}

Diamonds are the ultimate expression of love. Their ancient and timeless allure continues to influence consumer emotions and behaviours across continents, cultures and age groups. Analysts are predicting a sustained supplydemand shortfall in the years ahead which will trend diamond prices generally upwards. With positive long-term industry fundamentals, one cannot help but wonder why funding for diamond exploration and development projects is so scarce.

Investment in exploration across commodities - including diamonds - has been declining for a number of years, reaching a historic eleven-year low early in 2017. The lack of major diamond discoveries in recent years has done little to strengthen the case for investing in diamond projects, yet no new discoveries can be made without investment in exploration.

Global estimates of known carats in the ground stand currently at 2.5 billion carats, which equates to around 18 years of production at current levels of 140 million carats (mct) per annum. Sustainable replenishment of depleting diamond resources is possible only through the development of new discoveries. This is what junior explorers are best at - but they need investors to fund their evaluation activities from early in the project development continuum.

Junior explorers usually rely on equity financing to fund their early stage exploration and resource development until such time as an Indicated Resource is declared, along with completion of a bankable Feasibility Study (BFS) and debt funding becomes potentially accessible. With availability of traditional forms of financing becoming increasingly constrained, miners are considering alternative financing options.

\section{Diamond industry fundamentals}

Diamonds are traditionally less prone to volatility and uncertainty than mainstream mineral commodities. With almost no exposure to speculative capital (roughly 1\%), diamonds have proven significantly more stable than other tangible assets like gold and silver. Gold, on the other hand, has a speculative investment share of approximately $40 \%$, and as a result is highly volatile (Figure 1) (Duffield and Shellhas, 2013).

Diamond prices over the long term depend on consumer-driven supply-demand dynamics and economic growth. Favourable supply and demand fundamentals have led many industry experts to believe that diamonds will be among the top performing tangible assets for years. In fact, it is anticipated that diamond prices will outperform gold for the better part of the next decade, hitting annual record highs through 2020. Short-term speculative bubbles are to be expected within the rough diamond trade, but the polished market is generally more stable.

* Botswana Diamonds plc. Botswana.

(C) The Southern African Institute of Mining and Metallurgy, 2019. ISSN 2225-6253. This paper was first presented at the Diamonds - Source to Use 2018 Conference, 11-13 June 2018, Birchwood Hotel and OR Tambo Conference Centre, JetPark, Johannesburg, South Africa. 


\section{Financing diamond projects}

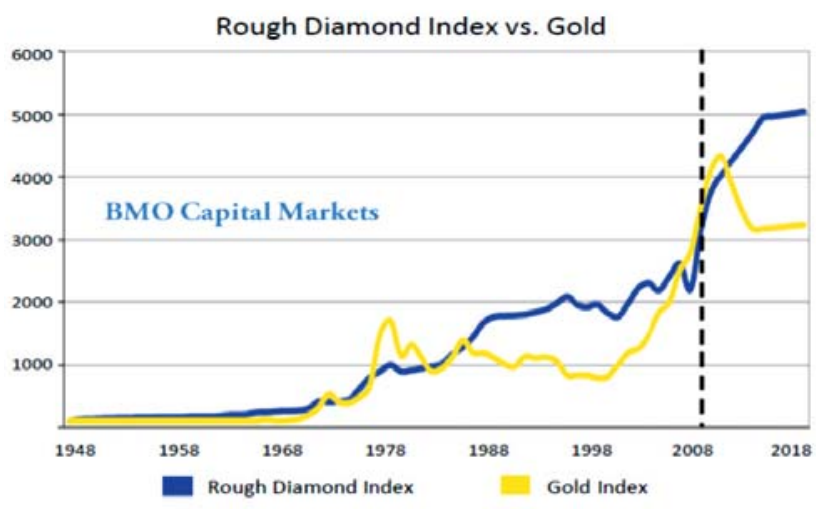

Figure 1-Historical price volatility of rough diamonds compared to gold (from Duffield and Shellhas, 2013)

New investment mechanisms have been introduced in recent years to stimulate investment in diamonds. In August 2017, the Indian Commodity Exchange (ICEX) became the world's first exchange to start trading in diamond futures contracts; shortly thereafter, India's Multi Commodity Exchange (MCX) also applied for the launch of futures trading in diamonds. Although it is still early days to assess the success of some of these mechanisms, there are clear indications that diamonds are beginning to attract interest as an investment category.

The supply-demand outlook is modestly optimistic (Figure 3); however, the diamond industry faces three key challenges - namely the slowdown in demand for diamond jewellery, the impact of laboratory-grown diamonds, and the financial stability of the midstream segment of the value chain (Bain \& Company, 2017).

In an effort to address such key challenges, rough diamond producers are investing significantly to promote diamond sales; an estimated \$150 million was invested in generic and branded marketing in 2017, representing an increase of about $50 \%$ from recent years. This was in addition to retailers' own marketing spend (Bain \& Company, 2017). The diamond industry has recently mobilized to fill the gap in generic consumer advertising left by De Beers, who stopped promoting diamonds for the whole industry in the early 2000s. A new trade body called the DPA (Diamond Producers Association) has a $\$ 60$ million annual budget to attempt to reinvigorate the category and drive future consumer demand, particularly targeting millennials.

Three new diamond mines have come on stream during 2017: Stornoway's Renard and Mountain Province's Gahcho Kué in Canada, and Firestone's Liqhobong in Lesotho. New supply from two of these mines may offset the loss of production from Alrosa's Mir mine - which remains closed indefinitely - with limited impact on the long-term supply forecast (The Diamond Loupe, 2017; Ziminsky, 2017b).

Despite the challenges that the diamond industry is facing on many fronts, the diamond market's long-term outlook remains positive with rough diamond demand expected to grow $1-4 \%$ per annum and rough diamond supply remaining stable until 2030. The 'base case' forecast for a sustained supply-demand shortfall in the years ahead will trend diamond prices generally upwards (Bain \& Company, 2017).

\section{Zimnisky Global Rough Diamond Price Index} 10 Year Quarterly

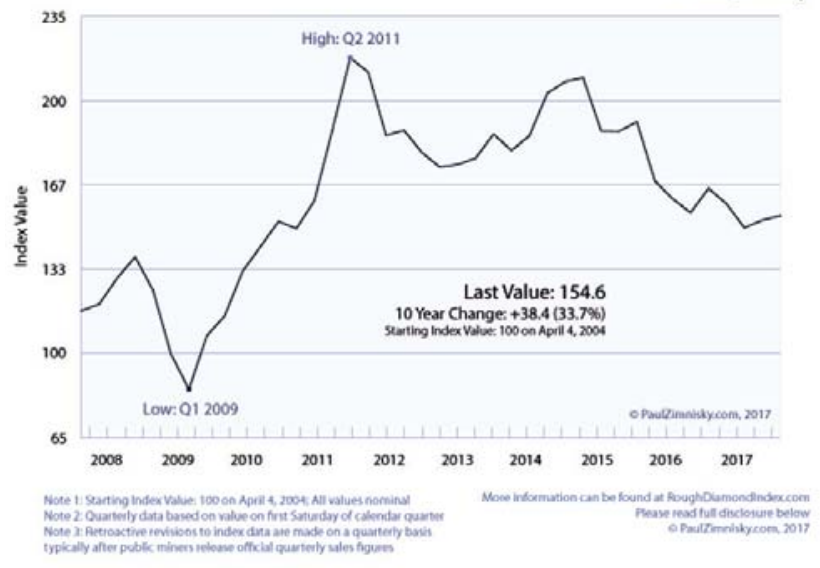

Figure 2-Rough diamond price performance over the last decade (Ziminsky, 2017a)

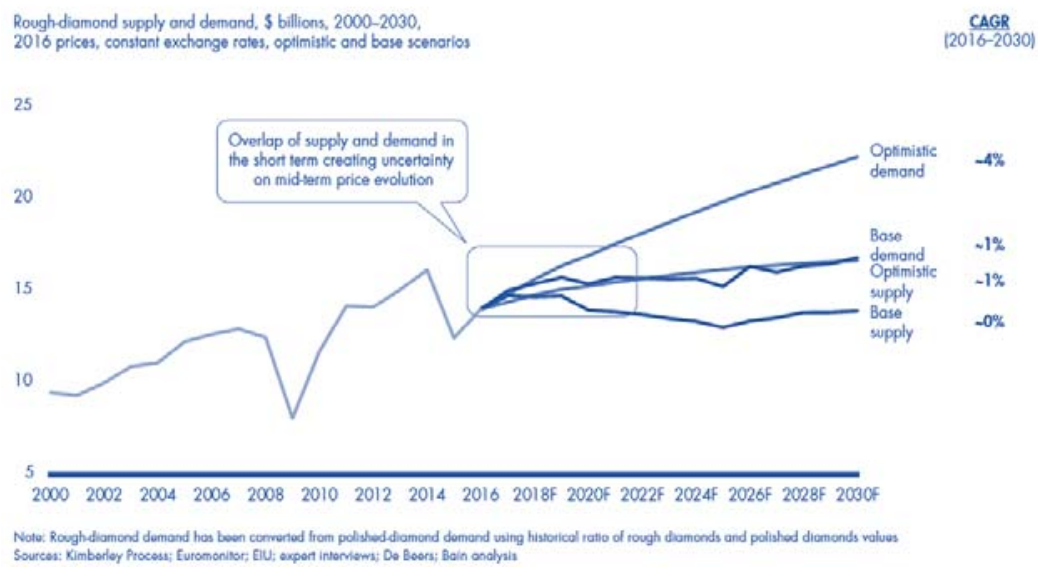

Figure 3-Diamond supply-demand optimistic and base scenario (Bain \& Company, 2017) 


\section{Financing diamond projects}

\section{Exploring for diamonds: risk and uncertainty}

Exploring for diamonds is a business with high uncertainty and risk and little, if any, guarantee of reward. The primary risk of exploration lies with the mineralization in the ground; this is inherent in any form of mineral exploration, but diamond mineralization has a higher degree of complexity than other types. Such primary risk is partly mitigated by increasingly refining the understanding of the mineralization through a process of systematic mineral resource development which leverages new and past geological data. International codes such as SAMREC, JORC, or CIM govern such processes and stipulate the reporting parameters for the different categories of mineralization and Mineral Resource (Figure 4).

On top of the geological and resource risk are country and political risks: explorers must go where the right geology and diamonds can be found, and neither of these follow humanimposed country boundaries (Figure 5). Risk appetite differs from one exploration company to the next, and more markedly between majors and juniors. Some juniors are prepared to trade some political risk for the advantage of 'being at the right address', i.e. where the geological risk is lower (Teeling, 2017).

Risk mitigation in this respect requires a careful and ongoing assessment of prospectivity versus country and political risk, and ease of doing business. While geology remains unchanged (although understanding of it might improve), the investment attractiveness of a particular country (Figure 6) may change over time, depending on political, social, and economic circumstances.

The fiscal regime of a prospective diamond country is a key influencing factor in investment decisions. Even more important are government policies on local ownership and indigenization and any legislated free-carry government interest, particularly when these are introduced suddenly. A stable and predictable regulatory regime is conducive to a viable investment climate, while sudden legislative changes in areas affecting the economics of an investment risk - such as state ownership and royalties - can have a chilling effect on investment (Leon, 2018).
The collapse of the commodities boom post-2011 has led to an upswing in resource nationalism and increasing indigenization requirements in some sub-Saharan African countries (Table I) (Davenport, 2016). A recent change to the Tanzanian mining regulations requires that government have

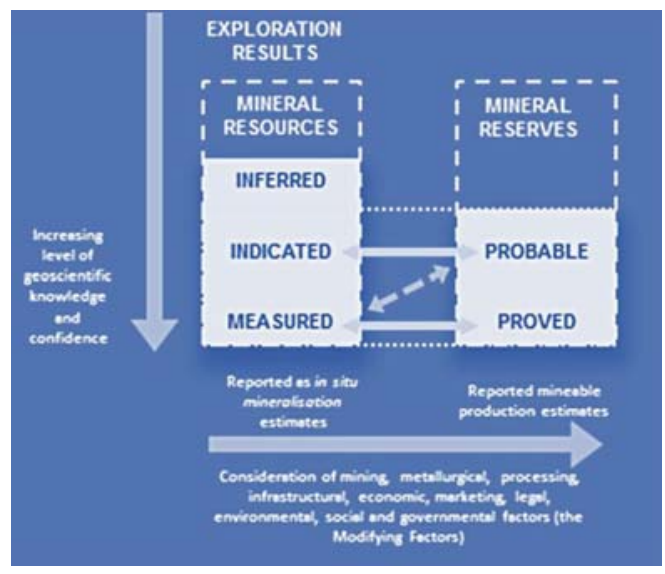

Figure 4-Classification of Mineral Resources (after SAMREC, 2016)

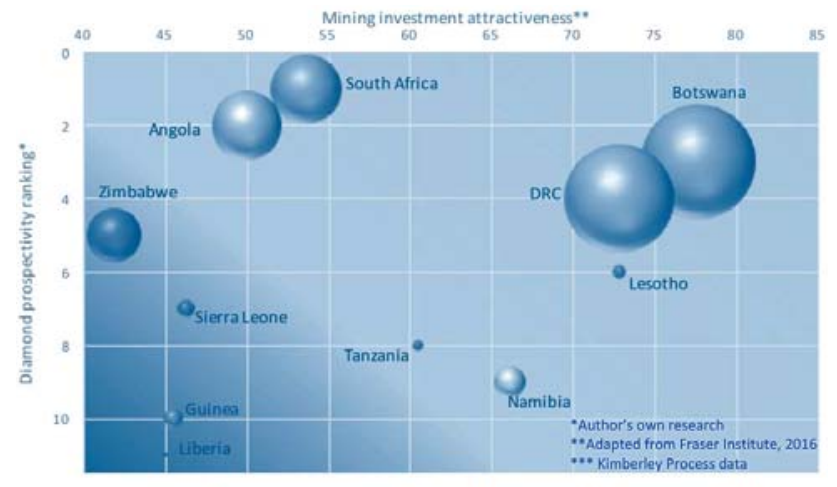

Cumulative diamond production (2007-2016) for selected African countries *..

Figure 6-Mining investment attractiveness for selected African countries (Campbell, 2017)
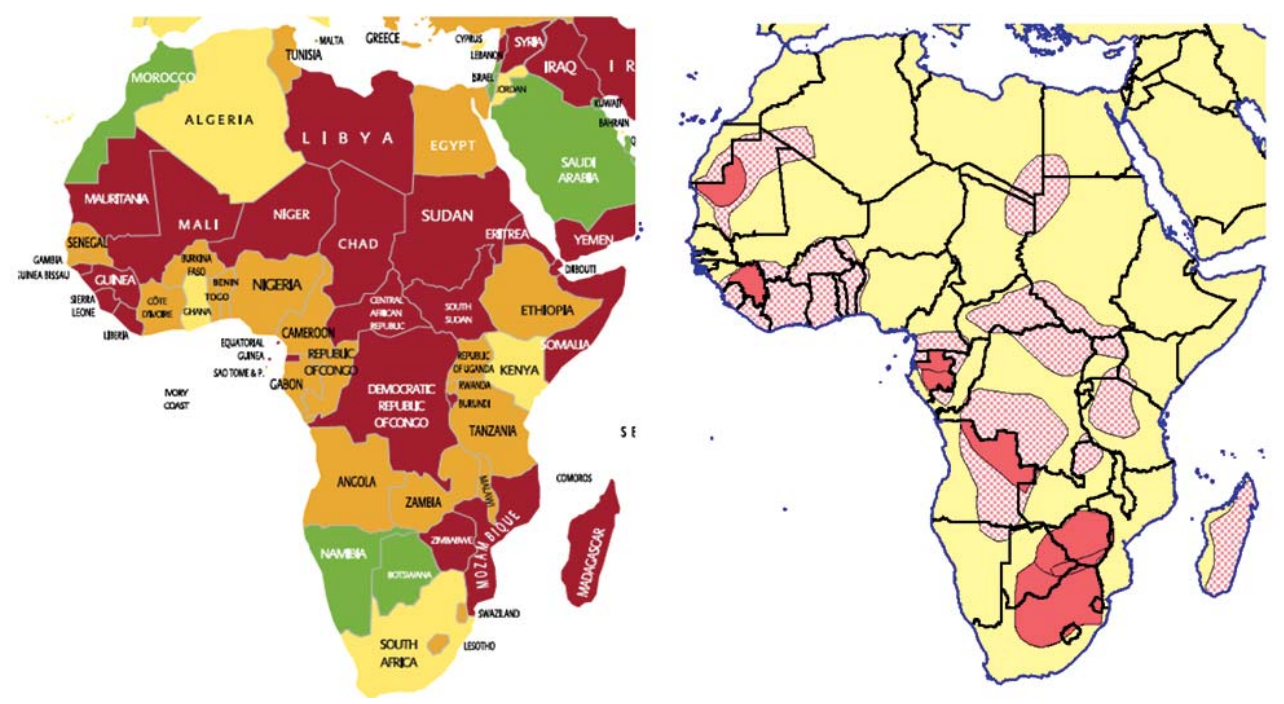

Figure 5-Africa country risk map (adapted from Euler Hermes, 2017) and Africa craton map (after Campbell, 2005) 


\section{Financing diamond projects}

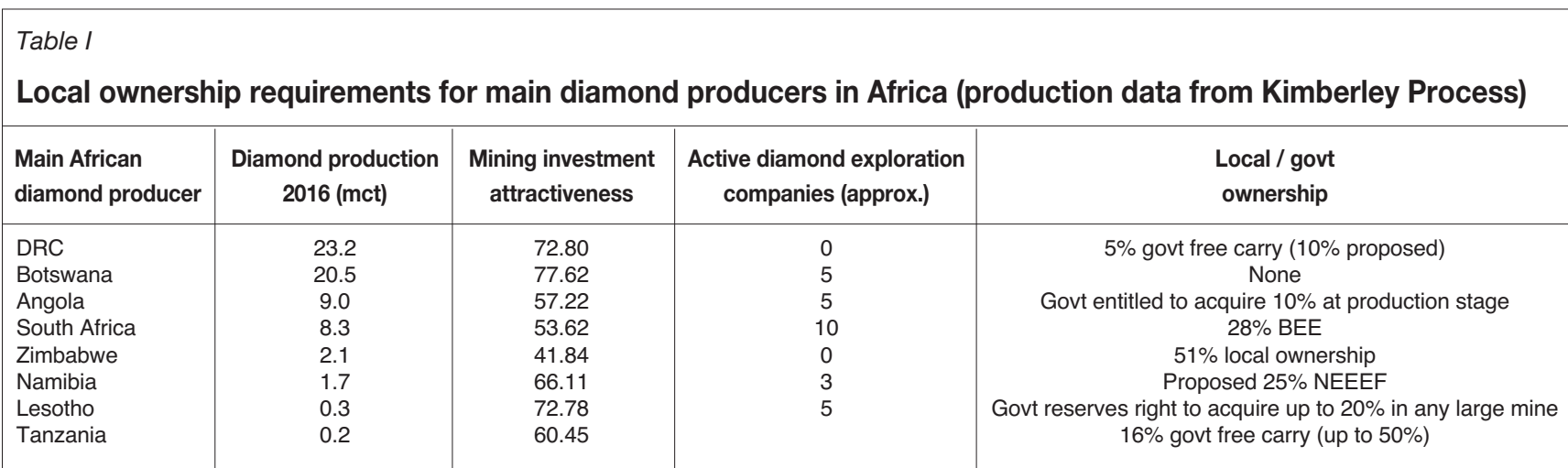

a $16 \%$ free carry interest in any future mining project (this was accompanied by a blanket ban on the export of unprocessed minerals). Namibia appears to be following the South African economic empowerment approach, while the new Zimbabwe government has retained the 51\% indigenization requirement for platinum and diamonds, which it had initially considered repealing. The Angolan government is entitled to hold a $10 \%$ equity in mining production through a State-owned company. Botswana is the only diamond-producing country in Africa to require no local ownership in mining companies.

\section{The burden of resource development}

Explorers operate at the tough end of the diamond funding pipeline, where the odds are stacked against them due to prevalent risk aversion and scepticism. As confidence in the mineralization grows, so does investors' appetite (Figure 7). However, the resource risk mitigation process attracts additional costs which increase exponentially as a project advances through the development pipeline.

While the announcement of a new diamond discovery generates positive sentiment in the market - often with a favourable impact on share price - this important milestone for any explorer is only the beginning of the demanding and capital-intensive process of proving up a diamond resource. This is a journey that can span decades, and which requires the ability to maximize optionality by adopting a phased approach to resource development, with targets set by phase and clearly identified triggers and decision points, in order to extract value or cut losses early (Still, 2016).

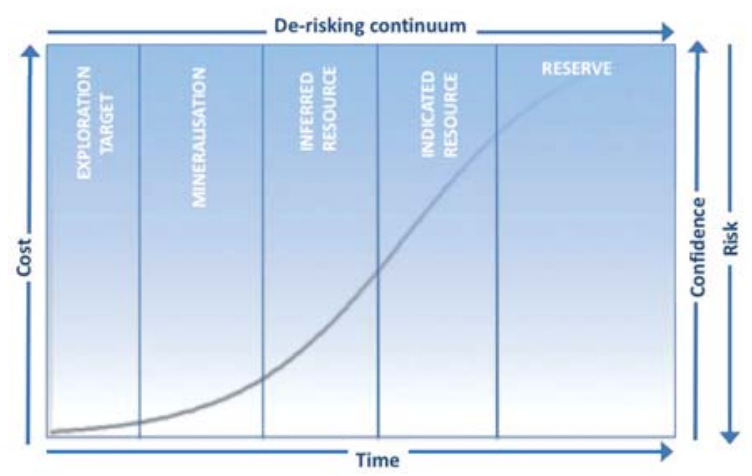

Figure 7-The project development de-risking continuum
Explorers with a track record of commercializing discoveries know that technology and deep expertise are key enablers when it comes to mitigating risk and extracting early value. To quote Dr. John Teeling, 'Exploration begins anew every 20 years with improvement in technology' (Teeling, 2017).

Technology plays a fundamental role throughout the diamond pipeline, from early exploration through evaluation, mine design, and diamond recovery, and further downstream where technology is used to identify, grade, and mark natural diamonds. Considerable improvements have been made in diamond recovery technology, especially in the identification of diamonds within kimberlite prior to crushing using X-ray transmission (XRT) technology, such as the XRT sorters installed at Karowe (Tassell, 2017). Nevertheless, breakage of diamonds during processing remains one of the key risk factors that producers have to mitigate in order to maximize value, or even determine viability. Unlike other commodities, diamonds are valued according to nonlinear models; diamond size is the main driver of diamond price, along with colour, quality, and shape.

For established producers, especially mines that are known to yield large stones, the public acknowledgement of diamond breakage (most recently by Gem Diamonds and Stornoway Diamonds) can be a downgrading factor in terms of investor confidence. On the other hand, the recovery of a large, valuable stone constitutes a 'material event' that can influence the company's share price and the market's perception of the company's value. Such events are more material the smaller the size of the company and the higher the value of the diamonds recovered (Ziminsky, 2017c).

Material events require prompt and full disclosure to markets and regulators; their newsworthiness, however, depends on the company's appetite for exposure and publicity. Privately owned diamond mining companies have seldom publicized the recovery of individual diamonds, although this is changing for many of them. For small diamond miners, on the other hand, the recovery of a single high-value diamond is a newsworthy event and its announcement can have a significant impact on share price.

The journey from discovery through evaluation to production can differ depending on the geological settings and jurisdictions, as well as the companies involved. The recent history of Karowe mine is a particularly telling example. 


\section{Financing diamond projects}

\section{The development of Karowe mine}

Karowe mine, located in the Orapa region of Botswana, is an open pit kimberlite operation and one of the world's top diamond producers by value. The mine began production in 2012 and has an anticipated life of mine of 15 years. Estimates for 2018 are 270 000-290 000 carats for a revenue of \$170-200 million. Since 2010, Karowe is fully owned by Lucara Diamond Corporation, a TSX and Stockholm Stock Exchange listed company with a market capitalisation in excess of $\mathrm{C} \$ 800$ million.

A highly profitable producer, Karowe has generated revenue in excess of $\$ 1.02$ billion to date, at an average price of $\$ 566$ per carat. The mine is a proven large stone producer, famous for its magnificent Type II diamonds. The second largest diamond ever found, the 1109 ct Lesedi La Rona, was unearthed at Karowe in 2015.

AK6 (now Karowe) was discovered by De Beers in 1969. The potential of AK6 was not apparent at the time of its discovery and early assessment in the 1970s and 1980s. One ought to consider that this was a time of economic stagflation, when high inflation combined with slow growth and high unemployment crippled the global economy. Worldwide, diamond sales were declining sharply and diamond prices collapsing. A radically transformed market and new strategic direction in the 2000s, coupled with a long-term outlook of declining diamond supply and increasing demand, prompted De Beers to reassess many of the uneconomic kimberlites discovered in the 1960s and 1970s using second-generation exploration technology and analytical techniques. AK6 was among these kimberlites.

The evaluation of AK6 took place in the ambit of the Boteti JV (51\% De Beers, 49\% African Diamonds). The process was fast-tracked to deliver the first mineral resource statement in 2007. Techno-economic studies were initiated in parallel to Phase 2, thereby further accelerating project development.

Contrasting strategic, corporate, and financial agendas, risk appetite, approach to mine development, and diamond pricing methodologies were pivotal to the strategic decisions that shaped the AK6 project. The valuation of the project by the different players was vastly different, with economics ranging from robust to marginal.

When De Beers became unable to finance the project in the aftermath of the Global Financial Crisis, African Diamonds proposed to buy out De Beers' share, realizing that the project had robust economics; however, they were unable to raise the necessary funds. The mining boom had ground to a halt in 2009 and investment activity in the mining sector had dropped dramatically. Not surprisingly, juniors were the hardest hit.
In 2009, Lucara Diamonds, facilitated by African Diamonds, was able to buy $70 \%$ of a $\$ 1$ billion business for $\$ 49$ million, proving once again that 'cash is king', and especially so at the bottom of the economic cycle. Lucara's market capitalisation prior to this acquisition was just $\mathrm{C} \$ 30$ million. In 2010, Lucara purchased African Diamonds' share at a $30 \%$ premium.

From an economic perspective, the AK6 story demonstrates that the right set of technical and corporate skills, coupled with the right opportunity and timing, can generate attractive returns for shareholders through increased share price (Figure 8)

African Diamonds raised cash at $2 \mathrm{p}$, listed at $7 \mathrm{p}$ in 2004, and sold AK6 for an equivalent 52 p. African Diamonds' exploration assets were spun off into Botswana Diamonds plc. The original shareholders of African Diamonds made forty times their money through shares in Botswana Diamonds and dividends and capital growth in Lucara Diamonds (Figure 9). Much of the experience that was hard won through the AK6-Karowe journey from a submarginal project to one of world's greatest diamond mines is today retained within the Botswana Diamonds team.

\section{Trends in exploration spend}

Investment in exploration across commodities has been declining for a number of years, reaching a historic elevenyear low early in 2017 (Figure 10). Moreover, the grassroots share of overall exploration budgets has been declining since the 1990s, while the shares of late-stage and minesite exploration budgets have been trending upward (Els, 2017).

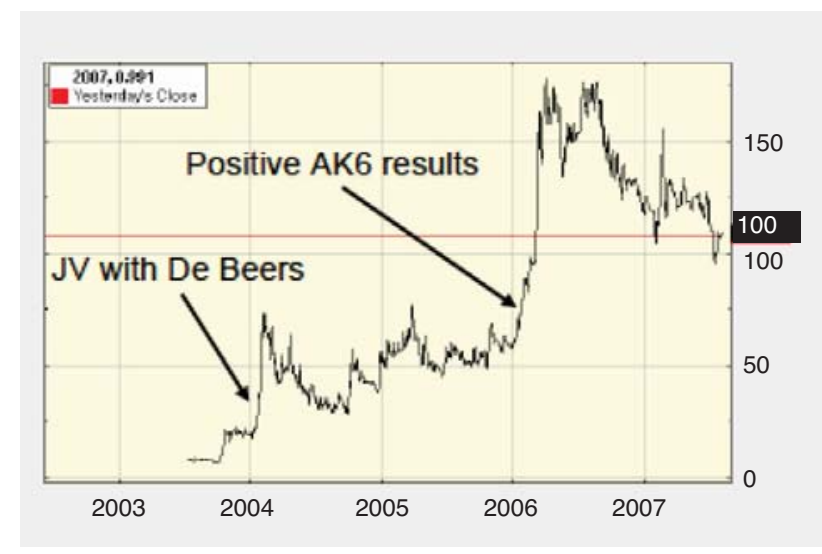

Figure 9-Impact of AK6 project development on AFD's share price 2004-2007 (source: advfn.com)

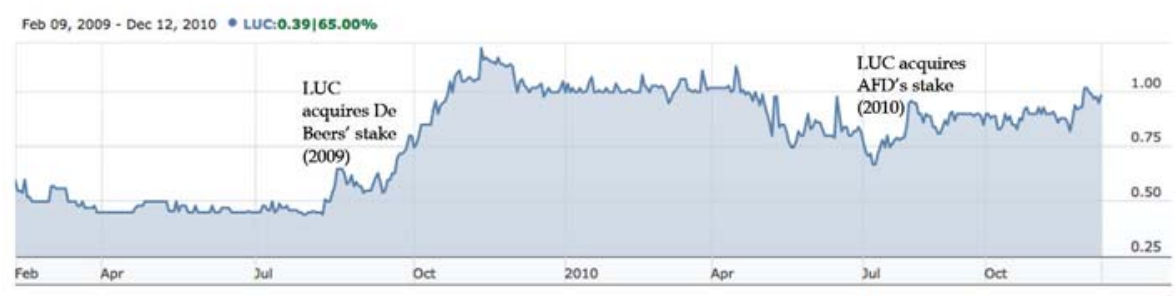

Figure 8-Impact of AK6 acquisition on Lucara Diamonds, share price 2009-2010 (source: morningstar.com) 


\section{Financing diamond projects}

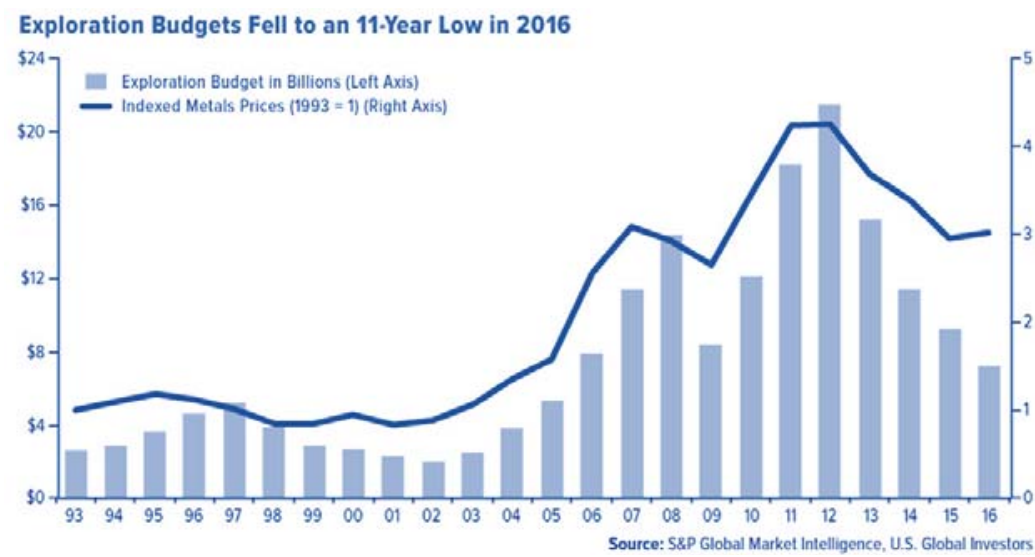

Figure 10-Global exploration budgets 1993-2016

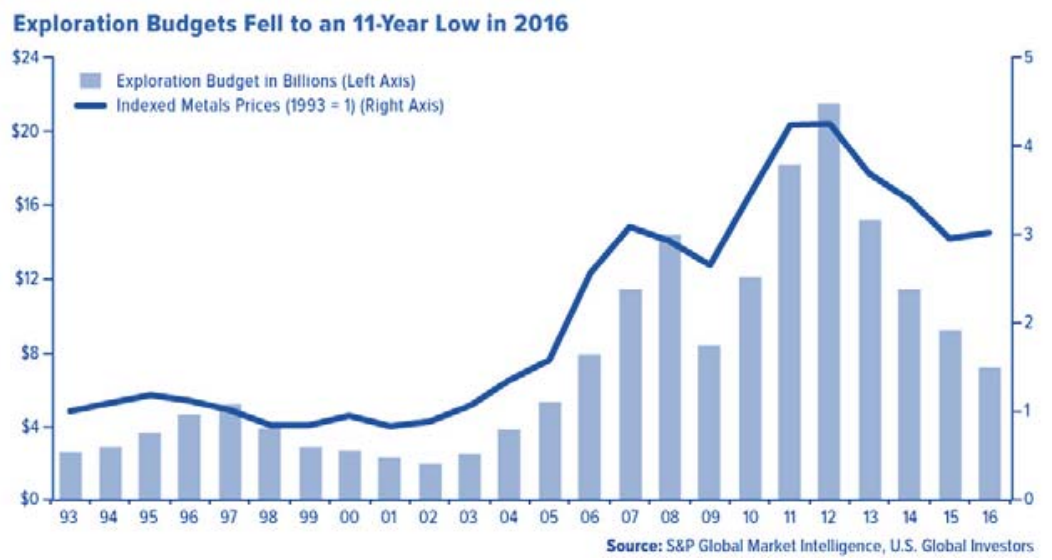

Figure 11-Exploration budget share by stage of development (source: mining.com)

Throughout 2016, the largest mining companies were responsible for the majority of exploration spending. For the third consecutive year, companies allocated more to minesite work than to grassroots exploration, as the former is perceived as a less expensive and less risky means of replenishing resources. With early-stage exploration being driven by the majors, overall spend on greenfield exploration fell to new lows, while proportionally more was spent on moving late-stage projects towards production or making them attractive for acquisition (mining.com, 2017)

(Figure 11).

Against this background of restricted exploration funding, investors' appetite for diamond exploration has been further curbed by the lack of new significant discoveries in the last decade (with the exception of Alrosa's Luele kimberlite at Luaxe in Angola and Lucara's Karowe mine in Botswana); as a result, funding for diamond exploration remains extremely tight. The paradox is that the lower the exploration spend, the fewer the chances of new discoveries.

\section{Junior exploration funding}

The discoverers and developers of new economic deposits tend to be agile, fast, and innovative small-cap companies with a healthy appetite for risk. Exploration spend is the lifeblood, yet these juniors typically have no production cash flow to fund their exploration activities.

Funding of early stage exploration and resource development activities usually comes from 'family and friends' (Teeling, 2017) with some appetite for risk; only once an Indicated Resource is declared, along with completion of a BFS, does debt funding potentially become accessible. This is largely because institutional investors look for positive cash flows, low or mitigated risk, high returns and, preferably, some form of tax incentive.

As a company de-risks its projects, more value is unlocked for shareholders. The Lassonde curve (Figure 12) illustrates the value that the market attributes to each stage of the life-cycle of a mining company from exploration to production.

The discovery phase is high-risk, high-potential, and early investors can see substantial gains in a short timeframe. Once the mineralization is delineated, the project enters the development phase. This period can be accompanied by a lack of news as companies work on economic studies, which leads to sell-off by many impatient investors. When a company finally begins construction, the reality of cash flow becomes apparent, and institutional 


\section{Financing diamond projects}

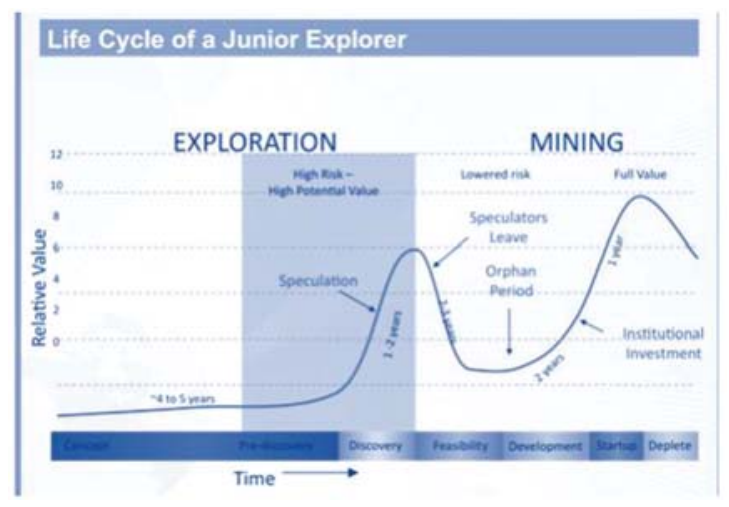

Figure 12-Lassonde curve illustrating the life-cyle of a junior explorer (source: Exploration Insights, 2016)

investors begin to enter the scene. From there onwards, it is up to the company to maintain a healthy and active pipeline to ensure that value creation outpaces depletion (Palisade Research, 2017).

The intervening phase between discovery and development is the most critical for junior explorers. As speculators exit the scene, the company enters an 'orphan period' from which it may not recover unless funding is obtained. It is precisely at this stage that junior incubators have a crucial role to play. Yet, these are few and far between, and particularly so in the diamond exploration space. Internationally, companies such as the 162 Group, HDI (Hunter Dickinson Inc.), and the Lundin Group have operated effectively in the resources space by applying a mix of entrepreneurial skills, business experience, and risk appetite to identify viable opportunities for new ventures.

HDI has raised more than $\mathrm{C} \$ 1.9$ billion in equity financing since 1985 and established a large network of institutional and retail investors in leading financial centres; together with their affiliated companies, they have successfully acquired and developed mineral properties with high potential for value growth.
The remarkably successful Lundin Group has recently been shifting its focus towards the consolidation of the midsize mining space (Business News Network, 2017).

The 162 Group focuses on high-potential natural resource start-ups, providing seed capital and initial management and taking the venture to market normally within three years. Over time the 162 Group has established 15 listed resources companies with interests across the globe, including AIMlisted Botswana Diamonds which is actively exploring in South Africa and Botswana.

The perception that Canadian and Australian institutional investors may be less risk-averse than their London-based counterparts has prompted certain London-listed junior miners to seek secondary listings in Toronto in the hope of higher valuations (Denina and Lewis, 2017). From 2009 to 2016, equity financings for mining companies listed on the Toronto Stock Exchange or TSX Venture Exchange fell by 58\% (Eastman, Graves, and Mariage, 2017). However, the growing number of mergers and acquisitions and the reemergence of IPOs on the TSX-V during 2017 are signs that some confidence is returning to the junior mining sector (PwC, 2017).

\section{Financing of diamond projects - what are the alternatives?}

The availability of financing through 'traditional' equity and debt markets has been constrained by falling commodity prices, a legacy of cost inflation during the supercycle, and continued uncertainty in the international economy. Miners, however, need to generate funding for operations, including new developments and expansions. Mining companies with substantial debt burdens need to reduce the existing debt on their balance sheets (Eastman, Graves, and Mariage, 2017).

According to a recent study of private capital in the resources sector, two-thirds of institutional investors have shown diminished appetite for the mining and metals sector, primarily due to volatility and uncertainty. In contrast, private capital investment in the mining and metals sector has been increasing through a range of investment vehicles

\begin{tabular}{|c|c|c|c|}
\hline Stock exchange & Mining-specific reporting requirements (post-listing) & Mineral reporting standard & Diamond companies (selected) \\
\hline ASX & $\begin{array}{l}\text { Annual and half-year financial report } \\
\text { Quarterly report by CP on production and development activities } \\
\text { (incl. expenditure); exploration activities; mineral results and ore results }\end{array}$ & JORC & $\begin{array}{l}\text { Merlin } \\
\text { Lucapa }\end{array}$ \\
\hline JSE & $\begin{array}{l}\text { Annual and quarterly financial report. } \\
\text { Description of exploration and mining activities by CP; } \\
\text { Mineral Resource and Reserve statement }\end{array}$ & SAMREC & Trans-Hex \\
\hline TSX/TSX-V & Annual and quarterly financial report. & CIM (NI 43-101) & $\begin{array}{c}\text { Diamcor } \\
\text { DFI } \\
\text { Kennady } \\
\text { Lucara } \\
\text { Mountain Province } \\
\text { Peregrine } \\
\text { Rockwell } \\
\text { Stornoway } \\
\text { Tsodilo } \\
\text { Dundee Minerals }\end{array}$ \\
\hline LSE/AIM & $\begin{array}{l}\text { Annual and half-year financial report. } \\
\text { Interim management statement. } \\
\text { Resource updates by CP (AIM). }\end{array}$ & $\begin{array}{l}\text { JORC, SAMREC, CIM, } \\
\text { other selected codes }\end{array}$ & $\begin{array}{l}\text { Botswana Diamonds } \\
\text { Firestone } \\
\text { Petra } \\
\text { Blue Rock }\end{array}$ \\
\hline
\end{tabular}




\section{Financing diamond projects}

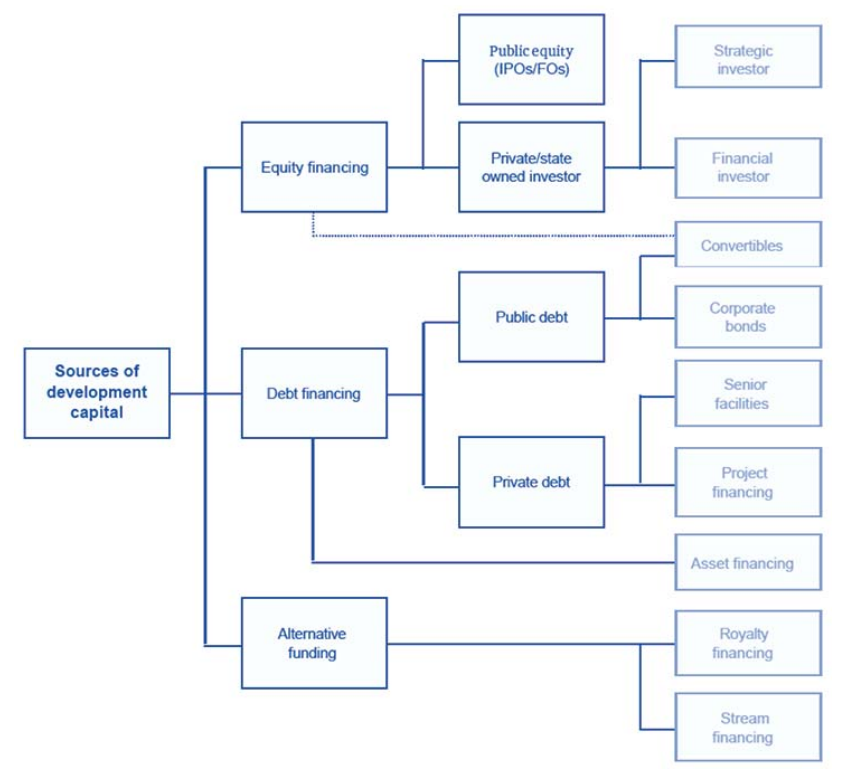

Figure 13-Financing options for mining companies (after PwC, 2013)

and strategies, including private equity and debt funds (Els, 2016).

As the global mining industry slowly recovers, many mining companies are turning to emerging or alternative financing options, chiefly mineral royalties and revenue streaming (Figure 13). Both options are seen as better suited to junior and mid-tier miners, as they attract investors with higher risk appetite and faster decision-making processes than traditional banks; moreover, these options involve sequences of payments rather than large upfront risk capital (Grieve, 2018). Such alternative financing options, however, are often inaccessible to early stage 'greenfield' project developers (Eastman, Graves, and Mariage, 2017).

While royalties have been in use in the mining industry for a long time but have only recently become mainstream options for generating funds, stream arrangements were only introduced in 2004 for precious metals, and have recently extended to other commodities such as base metals and diamonds. Both options share some common features and each has its advantages and disadvantages, as illustrated below.

Streaming finance is particularly applicable to countries in legislative flux like South Africa, as streamers are not concerned with equity and are thus less deterred (Grieve, 2018).

In 2014 Stornoway Diamonds made history by securing C\$944 million to develop the Renard project through a combination of debt, equity, and revenue streaming. It was the biggest project financing package for a publicly listed diamond company. The deal was designed to fully fund the mine construction through to completion and, although dilutive to the operation's NPV, it allowed the project to move forward without risk of delays due to capital constraints (van Praet, 2014).

An emerging alternative funding model is crowdfunding, or CSEF (crowdsourced equity funding). Crowdfunding enables project owners to raise funds through secured online platforms from a large number of small investors who can now own equity in an emerging mining company for as little as $\$ 500$. Unlike 'crowdselling', a common strategy practiced by institutional investors which left many mineral exploration companies on the brink of insolvency (Lasley, 2016), crowdfunding has the ability to reach a vast number of potential investors through social networks, thereby expanding the pool of potential investors far beyond the confines of banks, venture capitalists, and other mining companies. However, it is imperative that communications with this audience be frequent, direct, and transparent; and the information clear and current. This will require a major shift in the marketing strategy of most mining companies.

Dedicated crowdfunding platforms for mining companies have been launched in Canada and Australia and others are in development, such as ResourceFunding in the UK. Mining companies using such online investment platforms commit to transparency of information to investors and undergo rigorous due diligence processes which are designed to protect the crowd (Breytenbach 2016). Regulators in Canada and the USA have already adopted rules allowing the sale and purchase of securities via crowdfunding portals. Lobbying is ongoing in Australia to change the legislation in support of crowdfunding (Lasley, 2016; Banks, 2016)

Crowdfunding is changing the investment landscape by removing barriers for investors and connecting investors and mining companies.

\section{Discussion}

With solid industry fundamentals, indications of growing interest in diamonds as an investment category, and alternative financing mechanisms available, why is it that junior diamond explorers struggle to attract investment early in the project development continuum? Where and how can juniors source sufficient funding to navigate the 'orphan period' between the 'friends and family' and the Inferred Resource stage? This is where mining project incubators could play a crucial role.

The South African government has identified small business incubators as a priority, yet it remains unclear how these incubators would get access to finance when they don't have their own, government funds are limited, and banks are averse to funding start-ups.

The recent introduction of Section 12J of the Income Tax Act incentive structure allows companies and individuals to receive a tax deduction of $28 \%$ on their investments. This may entice more individuals to invest in small businesses, particularly high-risk, high-growth start-ups. Moreover, investments into a Section 12J venture capital company can attract enterprise development or sustainable development points, where the underlying investments qualify. Will this incentive be enough to stimulate the establishment of mining project incubators in South Africa?

The portfolio of projects of the JSS Empowerment Mining Fund, a Section 12J company launched in 2017, is primarily in the coal mining sector (Odendaal, 2017). Coal is the only South African resource sector to have been leading the conversation on mining industry incubators (SRK, 2017), which is not surprising when one considers that over $90 \%$ of South Africa's energy is generated from coal. Coal mining is, however, a relatively low-risk proposition, and particularly so compared to diamonds. 


\section{Financing diamond projects}

The JSE, South Africa's long-established stock exchange, prides itself in having the world's highest migration rate from the small-cap secondary board (the AltX) to the main listing platform. Why then are so many junior explorers active in South Africa not listed on AltX? Perhaps the value proposition of some of the firms operating as JSE/AltX sponsors or designated advisers could be enhanced by offering business incubator services to potential new entrants.

The rise of crowdfunding in mining presents an attractive option for juniors seeking exploration seed funding. Could it become a viable alternative at a time when traditional methods for raising exploration capital are failing junior explorers? Could it become the future of fundraising?

\section{Conclusions}

Diamond exploration is a complex business with a high failure rate. It requires trusted teams of 'mine finders' with proven skills, deep commitment, and healthy doses of tenacity and optimism.

It requires the careful, ongoing assessment of the interplay between geological and country risks and the agility to respond promptly to any changes in the latter - be they improvements in fiscal regime or sudden indigenization legislative changes.

It also requires financing: right from the early stages, when public listing is neither viable nor acceptable by the main stock exchanges, and increasingly so through the evaluation stage, when confidence in the mineralization is not yet sufficient to entice the more risk-averse investors.

Entrepreneurs with a following and isolated 'junior incubators' have had a crucial role to play in the growth of certain diamond exploration companies; however, these are few and far between. New and alternative financing mechanisms have appeared in the recent years, including crowdfunding. Their viability in the diamond exploration space, however, remains to be ascertained.

\section{References}

Bain \& Company. 2017. The global diamond industry 2017. http://www.bain.com/publications/articles/global-diamond-industryreport-2017.aspx [accessed 11 February 2018].

BANKs, J. 2016. Crowdfunding - a credible new source of investment for mining? http://www.stratum-international.com/blog/crowdfundinginvestment-in-mining/ [accessed 10 March 2018].

BREYTENBACH, M. 2016. Alternative fundraising model seen flourishing but regulatory issues could stifle uptake in South Africa. http://www.miningweekly.com/print-version/despite-game-changingexpectations-regulatory-challenges-remain-key-concern-ofcrowdfunding-for-mining-sector-2016-05-20 [accessed 10 March 2018].

Business NEwS NETWORK. 2017. Rick Rule interviews Lukas Lundin on what sets the Lundin Group apart from competitors.

https://www.bnn.ca/investment-trends/video/rick-rule-interviews-lukaslundin-on-what-sets-the-lundin-group-apart-from-competitors 1264442 [accessed 18 February 2018].

CAMPBELL, J.A.H. 2005. The continuing transformation of De Beers - a case study. Presentation to the Executive MBA Study Tour of South Africa. Tanaka Business School, Imperial College, London, UK

CAmpBell, J.A.H. 2017. Country models that are working and why. Panel discussion at the Africa Mining Summit, Gaborone, Botswana.

DAVEPORT, J. 2016. Time for African countries to rethink mining policies.

https://www.howwemadeitinafrica.com/time-african-countries-rethink-miningpolicies/55089/ [Accessed 9 February 2018]

DeninA, C. and LewIS, B. 2017. Small mining companies shun London market after IPO flops. https://www.reuters.com/article/us-mining-ipo/smallmining-companies-shun-london-market-after-ipo-flops-idUSKBN1CU26A [accessed 10 March 2018].
DufField, C. ANd Shellhas, K. 2013. Could diamonds outperform gold this decade?http://www.traderplanet.com/articles/view/163898-coulddiamonds-outperform-gold-this-decade-gld/ [accessed 1 March 2018].

EASTMAn, N., Graves, B., and Mariage, F. 2017. Global financing alternatives: a primer on royalty and stream financing. https://gettingthedeal through.com/area/22/article/29109/mining-2017-global-financingalternatives-primer-royalty-stream-financing/ [Accessed 11 February 2018].

ELS, F. 2016. Private capital is ready to invest $\$ 7$ billion in mining. http://www.mining.com/private-capital-is-ready-to-invest-7-billion-inmining/ [Accessed 10 March 2018].

ELs, F. 2017. Mining exploration spending drops to 11-year low. http://www.mining.com/greenfields-share-exploration-spending-dropsrecord-low/ [accessed 4 February 2018].

EULER HERMES. 2017. Country risk map Q1 2017. http://www.eulerhermes.com/ economic-research/publications/Pages/country-risk-map-q1 2017.aspx?postID=1033 [accessed 11 February 2018].

EXPLORATION InSIGHTS. 2016. Fatal flaws in the junior mining sector. https://www.explorationinsights.com/articles/fatal-flaws-in-the-juniormining-sector/ [accessed 10 March 2018]

GrIEvE, N. 2018. Juniors asked to consider royalty, streaming project finance deals. http://www.miningmx.com/news/energy/31512-junior-askedconsider-royalty-streaming-project-finance-deals/ [accessed 9 March 2018].

LASLEY, S. 2016. Crowdfunding awakens. https://www.miningnewsnorth.com/ story/2016/01/10/news/crowdfunding-awakens/3551.html [accessed 10 March 2018].

LEON, P. 2018. Mining sector needs a strong dose of Ramaphosa's Eskom treatment. https://www.businesslive.co.za/bd/opinion/2018-02-05mining-sector-needs-a-strong-dose-of-ramaphosas-eskom-treatment/ [accessed 2 March 2018].

ODENDAAL, N. 2017. JSS eyes R1bn capital raise to fund junior miners. $\mathrm{http} / / / w w w . e n g i n e e r i n g n e w s . c o . z a / a r t i c l e / j s s-e y e s-r 1 \mathrm{bn}$-capital-raise-tofund-junior-miners-2017-01-27 [accessed 10 March 2018].

Palisade Research. 2017. Junior mining's infamous guide to investing. https://palisade-research.com/junior-minings-infamous-guide-toinvesting/ [accessed 8 March 2018].

PwC. 2013. 3 things you need to know about alternative financing in the mining industry. https://www.pwc.co.uk/assets/pdf/alternative-financingin-the-mining-industry.pdf [accessed 22 February 2018].

PwC. 2017. Junior mine 2017: Confidence rekindled. https://www.pwc.com/ca/en/industries/mining/publications/junior-mine2017.html [accessed 9 March 2018].

SAMREC. 2016. South African Mineral Resource Committee. The South African Code for the Reporting of Exploration Results, Mineral Resources and Mineral Reserves (the SAMREC Code). 2016 Edition. http://www.samcode.co.za/codes/category/8-reportingcodes? download=120: samrec

SRK. 2017. Could coal mining be the SA mineral sectors business incubator? https://www.srk.co.za/en/za-could-coal-mining-be-sa-mineral-sectorsbusiness-incubator [accessed 10 March 2018].

STILL, R. 2016. Lessons from the exploration business. Presentation at the Junior Indaba, Johannesburg, South Africa.

TASSELL, A. 2017. XRT technology ushers a new era in diamond recovery. Modern Mining, May 2017.

TeELING, J. 2017. Have I a deal for you? Presentation at the Junior Indaba, Johannesburg, South Africa. http://www.juniorindaba.com/presentations [accessed 1 March 2018].

The DiamondLoupe.com. 2017. ALROSA rough Sales \$258M in August, to close Mir mine indefinitely.https://www.thediamondloupe.com/articles/201709-07/alrosa-rough-sales-258m-august-close-mir-mine-indefinitely [Accessed 25 February 2018].

VAN PRAET, N. 2014. Stornoway financing deal pushes Quebec's first diamond mine closer to reality. http://business.financialpost.com/commodities/ mining/stornoway-financing-deal-pushes-quebecs-first-diamond-minecloser-to-reality [accessed 8 March 2018].

Ziminsky, P. 2017a. Quarterly review of rough diamond prices in the 10 years since the Global Financial Crisis. http://www.paulzimnisky.com/10-yearquarter-by-quarter-recap-of-rough-diamond-prices-since-global-financialcrisis [accessed 4 February 2018].

Ziminsky, P. 2017b. 2018 Global diamond industry primer. http://www.paulzimnisky.com/2018-global-diamond-industry-primer [accessed 4 February 2018].

ZiмinsKy, P. 2017c. The discovery of newsworthy diamonds is increasing.

http://www.paulzimnisky.com/the-discovery-of-newsworthy-diamonds-isrising [accessed 4 February 2018]. 